\title{
Hybrids of HNBR and in situ polymerizable cyclic butylene terephthalate (CBT) oligomers: properties and dry sliding behavior
}

\author{
J. Karger-Kocsis ${ }^{1 *}$, D. Felhös ${ }^{1}$, T. Bárány ${ }^{2}$, T. Czigány ${ }^{2}$ \\ ${ }^{1}$ Institute for Composite Materials, University of Kaiserslautern, Erwin Schrödinger Str. 58, D-67663 Kaiserslautern, \\ Germany \\ ${ }^{2}$ Department of Polymer Engineering, Budapest University of Technology and Economics, Múegyetem rkp. 3., \\ H-1111 Budapest, Hungary
}

Received 2 May 2008; accepted in revised form 10 June 2008

\begin{abstract}
A peroxide curable hydrogenated nitrile rubber (HNBR) was modified by cyclic butylene terephthalate oligomer (CBT), added in 100 parts per hundred rubber (phr). CBT polymerization was expected to occur simultaneously with that of the curing of the $\mathrm{HNBR}$ rubber $\left(T=190^{\circ} \mathrm{C}, t=25 \mathrm{~min}\right)$.

Differential scanning calorimetry (DSC) indicated that only a minor part of CBT has been polymerized (pCBT) in the hybrid. Dynamic mechanical thermal analysis (DMTA) revealed that HNBR formed the continuous whereas (p)CBT the dispersed phase. Mechanical properties (hardness, tensile modulus, ultimate tensile strength and strain, tear strength) of the HNBR and HNBR/CBT were determined and collated. Tribological properties were investigated with pin(steel)-onplate(rubber) (POP), with roller(steel)-on-plate (rubber) (ROP), with oscillating steel cylinder on rubber plate (Fretting) test configurations. Coefficient of friction (COF) and specific wear rate of the HNBR-based systems were determined. It was found that the resistance to wear increases with CBT hybridization. On the other hand, COF did not change much with CBT content. The friction and wear characteristics strongly depended on the test configurations. The worn surface of the HNBR systems was inspected in scanning electron microscope (SEM) to conclude the typical wear mechanisms. SEM investigation showed that the CBT was predominantly recrystallized from its molten state under the curing conditions set. The well developed prism- and platy-like, micron-scaled CBT crystals were made responsible for the reinforcing effect observed.
\end{abstract}

Keywords: rubber, polymer blends and alloys, material testing, cyclic butylene terephthalate (CBT), sliding wear

\section{Introduction}

To combine thermoplastics with rubbers via melt blending has been always a preferred topic of research and development works which were mostly fuelled by economical reasons. The related efforts resulted in various types of thermoplastic elastomers (e.g. [1]) from which the thermoplastic dynamic vulcanizates [1-3] acquired considerable market segment. Nowadays, by marketing cyclic butylene terephthalate oligomers (CBT) a further interesting option appeared for rubber / thermoplas- tic combinations. CBT oligomers, having a melting range of $T=140-150^{\circ} \mathrm{C}$, can be polymerized into the corresponding linear polybutylene terephthalate in the presence of suitable catalysts. The temperature of the CBT polymerization is $T \geq 150^{\circ} \mathrm{C}$. The time needed for CBT polymerization depends on the type and amount of the catalyst, it is, however, usually less than $30 \mathrm{~min}$ at $T=190^{\circ} \mathrm{C}$. Attention should be paid to several peculiarities of the CBT polymerization including its final product. The CBT polymerization is athermic and it can be per- 
formed even below the melting temperature of the final polybutylene terephthalate $\left(T_{m} \approx 225^{\circ} \mathrm{C}\right)$ [4]. The isothermal polymerization $\left(T \approx 190-195^{\circ} \mathrm{C}\right)$, which is preferentially used, is followed by crystallization. Though some studies quoted that polymerization and crystallization are simultaneous (e.g. [5]) they are more likely consecutive processes [6]. The crystallization of the polymerized CBT, occurring in an undercooled melt at $T \approx 190-195^{\circ} \mathrm{C}$, seems to be a hardly controllable process [6]. The overall crystallinity of the in situ polymerized CBT is markedly higher than that of 'traditional' polybutylene terephthalates, produced by polycondensation [5-6]. Due to the above listed peculiarities we are using the abbreviation $\mathrm{pCBT}$ instead of the widely used PBT for the in situ polymerized CBT product further on.

Considering the fact that the usual polymerization temperature of CBT is close to the vulcanization temperature of different rubbers, hybrid rubber thermoplastics systems composed of crosslinked rubber and thermoplastic $\mathrm{pCBT}$ can be produced. A further benefit of this approach is that CBT, being a solid, powder-like material at ambient temperature can be easily incorporated in rubber mixes using the traditional mixing equipments. Park [7] already filed a patent on how to produce thermoplastic dynamic vulcanizates using CBT. Note that in the related system $\mathrm{pCBT}$ forms the continuous whereas the dynamically crosslinked rubber the disperse phase. The new method, exploiting the in situ polymerization of CBT in presence of curable rubber is more straightforward than the traditional dynamic vulcanization using high molecular mass linear polyesters ([8] and references therein).

Recall that the prerequisite of this rubber/thermoplastic combination is that the CBT polymerization is not affected by either the components of the cure recipe or the curing pathway of the rubber.

However, pCBT may be a beneficial polymeric additive for rubbers also when the rubber is 'statically' cured. It means that the CBT is incorporated in the curable rubber and it is polymerized to PCBT simultaneously with the curing of the rubber. The aim of this paper was to check the feasibility of this 'hybridization' using a suitable, high temperatureresistant rubber, namely hydrogenated nitrile rubber (HNBR). It was presumed, that peroxide curing of HNBR does not affect the polymerization of CBT. Next we report on the first results received on the structure, mechanical and sliding wear properties of HNBR/CBT hybrids.

\section{Experimental}

\subsection{Materials}

The composition of the peroxide curable HNBR was the following: HNBR (Therban ${ }^{\circledR}$ LT VP/KA 8882 of Lanxess, Leverkusen, Germany; acrylonitrile content: 21\%, Mooney viscosity, $\left.\operatorname{ML}(1+4) 100^{\circ} \mathrm{C}=74\right)-100$ part; diphenylaminebased thermostabilizer (Luvomaxx CDPA of Lehmann \& Voss, Hamburg, Germany) - 1.1 part; zinc-containing mercapto-benzimidazole compound (Vulcanox ${ }^{\circledR}$ ZMB 2/C5 of Lanxess) 0.4 part, t-butylperoxy-diisopropyl benzene (Perkadox 14-40 B-PD of Akzo-Nobel, Düren, Germany; active peroxide content: $40 \%$ ) -7.5 part, $\mathrm{MgO}$ 2 part, triallyl isocyanurate -1.5 part, $\mathrm{ZnO}-2$ part. This mix was produced separately and provided by Lanxess. The curing time of this base mix to reach $90 \%$ crosslinking was ca. $10 \mathrm{~min}$ at $T=175^{\circ} \mathrm{C}$. This peroxide curable HNBR was mixed with 100 parts per hundred rubber (phr) cyclic butylene terephthalate $\left(\mathrm{CBT}^{\circledR} 160\right.$, Cyclics Europe, Schwarzheide, Germany) on a two-roll mixing mill (LRM150BE of Labtech, Bangkok, Thailand) at ca. $40^{\circ} \mathrm{C}$ by setting a friction ratio of 1.15 . Note that this CBT contained already the polymerization catalyst. Curing of the HNBR both in presence and absence of CBT occurred at $T=190^{\circ} \mathrm{C}$ for $25 \mathrm{~min}$ in a laboratory press. Note that the temperature is higher and the time is longer than required for the HNBR alone as being adjusted to the polymerization of CBT [9]. Specimens for the investigations listed below were cut/punched from the compression molded sheets of ca. $2 \mathrm{~mm}$ thickness.

\subsection{Phase structure}

To get some insight in the structure of the HNBR/ CBT hybrid differential scanning calorimetry (DSC) and dynamic mechanical thermal analysis (DMTA) tests were run. DSC traces were registered by a DSC device (DSC821e of Mettler Toledo, Giessen, Germany) in a broad temperature range $\left(T=-100\right.$ to $\left.+260^{\circ} \mathrm{C}\right)$ at a heating and cooling rate of $20^{\circ} \mathrm{C} / \mathrm{min}$.

DMTA spectra were recorded on rectangular specimens (length $\times$ width $\times$ thickness $=20 \times 10 \times$ 
ca. $2 \mathrm{~mm}^{3}$ ) in tension mode as a function of temperature (from $-100^{\circ} \mathrm{C}$ to $+100^{\circ} \mathrm{C}$ ) and a frequency of $10 \mathrm{~Hz}$ using a Q800 device of TA Instruments (New Castle, DE, USA). Tests were run at a static preload $0.01 \mathrm{~N}$ with a superimposed sinusoidal $0.01 \%$ strain. Heating of the specimens occurred in a stepwise manner (temperature steps of $5^{\circ} \mathrm{C}$ were followed by an equilibration period of $3 \mathrm{~min}$ at each temperature).

\subsection{Property determination}

For the density determination the Archimedes principle (buoyancy method with water) was adopted according to ISO 1183. The Shore hardness of the rubbers was determined according to ISO 868 using a hardness measuring device of Zwick (Ulm, Germany). The Martens (earlier termed to universal) hardness (HM) was determined by the ISO 14577-1 (2002) standard using a Shimadzu DUH 202 device with a Vickers-type diamond indenter. Two types of microhardness tests were carried out. In the first case the maximum force and its holding time were $5 \mathrm{mN}$ and 2 second (s), respectively. In the second case the loading- deloading cycle was repeated at the same position of the indenter, and the load was increased in three consecutive steps. The maximum load values during the three steps were 1.6, 3.3 and $5 \mathrm{mN}$, respectively, with 2 s hold- ing time each. Tensile tests were carried out on $2 \mathrm{~mm}$ thick dumbbells (type: S1 according to DIN 53504) on a Zwick 1445 (Ulm, Germany) universal testing machine at a deformation rate of $500 \mathrm{~mm} / \mathrm{min}$. From the related stress-strain curves apart from the ultimate properties, the stress values at 100 and $200 \%$ elongations (termed M-100 and M-200, respectively) were also read (ISO 37). To determine the tear strength the recommendation of the ISO 34-1 standard was followed, i.e. angle-type specimen with cut was subjected to $500 \mathrm{~mm} / \mathrm{min}$ deformation rate.

\subsection{Sliding friction and wear}

Friction and wear characteristics were determined in pin(steel)-on-plate(rubber) (POP) configuration using a Wazau device (Berlin, Germany), in which a steel pin $\left(100 \mathrm{Cr} 6\right.$; arithmetical roughness, $R_{a}$, less than $1 \mu \mathrm{m}$ ) with a hemispherical tip of $10 \mathrm{~mm}$ diameter rotated along a circular path (diameter: $33 \mathrm{~mm}$ ). The pin was pushed against the rubber plate with a given load. The following parameters were selected for this configuration - normal load: $2 \mathrm{~N}$, sliding speed: $250 \mathrm{~mm} / \mathrm{s}$, duration: 1.5 hour (h). Measuring both the normal and the friction force components via a torque load cell the COF values were calculated and monitored during the test.
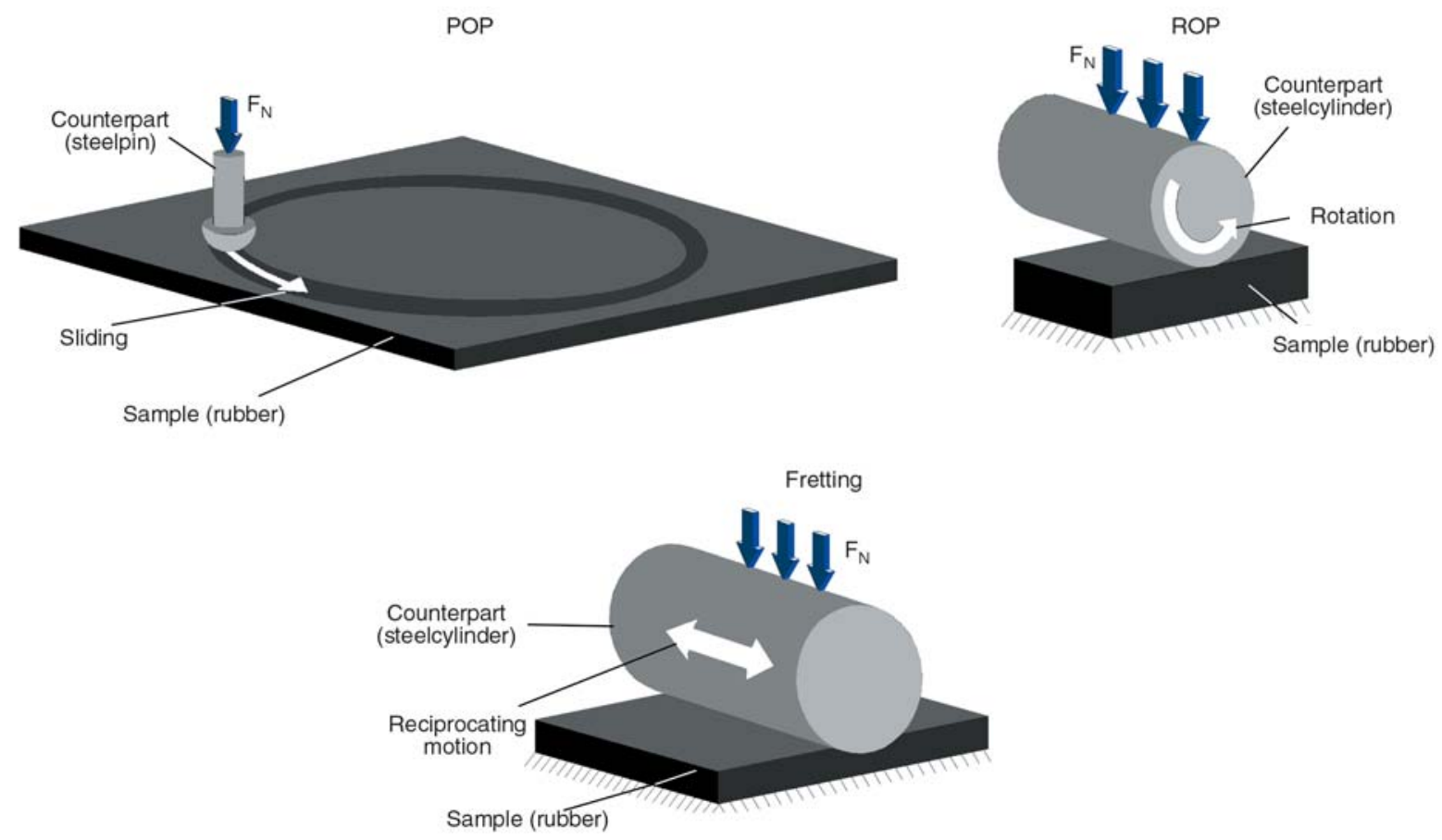

Figure 1. Schematic set-up of the tribotesting devices. Designations: pin(steel)-on-plate(rubber) (POP), roller(steel)-onplate(rubber) (ROP), oscillating steel cylinder on rubber plate (Fretting) 
To study the sliding wear a further test, termed to roller(steel)-on-plate(rubber) and referred to ROP, was also used. A rotating steel roller $(9 \mathrm{SMnPb} 28 \mathrm{k}$, diameter: $10 \mathrm{~mm}$, width: $20 \mathrm{~mm}, R_{a} \approx 0.9 \mu \mathrm{m}$ ) pressed against a rubber strip of $9 \mathrm{~mm}$ width in a SOP 3000 tribotester (Dr Tillwich GmbH, HorbAhldorf, Germany). The frictional force induced by the torque was measured online and thus the $\mathrm{COF}$ was registered during the test. The test parameters were - load: $<4 \mathrm{~N}$ (varied); sliding speed: $250 \mathrm{~mm} / \mathrm{s}$; duration: max. $1.5 \mathrm{~h}$.

In the third tribotest (fretting) a steel cylinder was oscillating on the surface of the fixed rubber specimen. The cylinder was pressed against the rubber with a given load. The diameter and the contact length of the cylinder $\left(R_{a} \approx 0.9 \mu \mathrm{m}\right)$ were 15 and $12 \mathrm{~mm}$, respectively. The applied normal load was $<30 \mathrm{~N}$ (varied), the frequency of the oscillation was set for 10 or $20 \mathrm{~Hz}$ (varied), the stroke selected was $<5 \mathrm{~mm}$ (varied), and the duration of the measurements was $3 \mathrm{~h}$.

The test configurations are depicted schematically in Figure 1.

The specific wear rates were determined by Equation (1):

$$
W_{s}=\frac{\Delta m}{\rho \cdot F \cdot L}
$$

where $\Delta m$ is the mass loss recorded gravimetrically, $\rho$ is the density, $F$ is the normal force and $L$ is the overall sliding distance.

Worn surfaces of the specimens were inspected in a scanning electron microscope (SEM; JSM5400 of Jeol, Tokyo, Japan). Prior to SEM investigation the specimens were sputtered with an $\mathrm{Au} / \mathrm{Pd}$ alloy using a device of Balzers (Lichtenstein).

\section{Results and discussion}

\subsection{Phase structure}

Figure 2 displays the DSC traces registered during heating $\left(1^{\text {st }}, 2^{\text {nd }}\right)$ and cooling (after $1^{\text {st }}$ heating). The glass transition $\left(T_{g}\right)$ step of the HNBR is well resolved at $T \approx-25^{\circ} \mathrm{C}$ during the $1^{\text {st }}$ heating. The next step at $T \approx 60^{\circ} \mathrm{C}$ should be assigned to the $T_{g}$ of pCBT. Note that neither CBT [10] nor HNBR shows any thermal transition at $T \approx 60^{\circ} \mathrm{C}$. So, CBT is likely polymerized, however, did not crystallize. This is quite surprising, but in line with recent

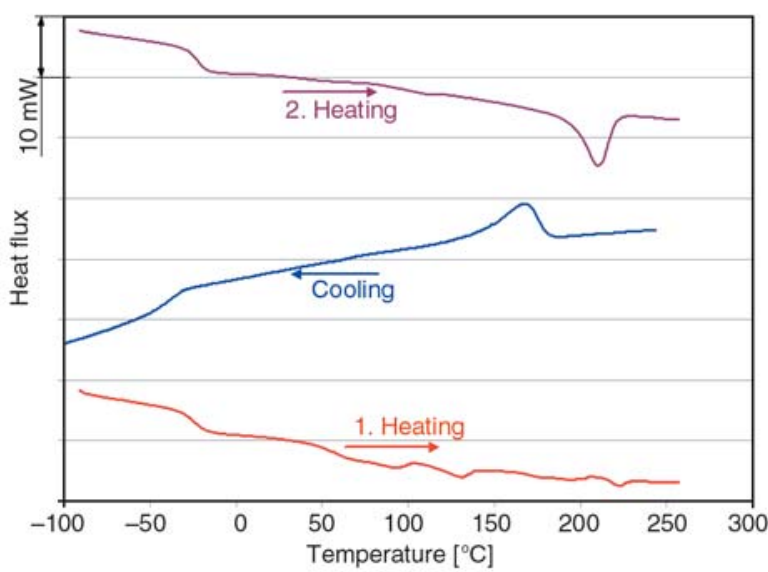

Figure 2. DSC traces registered on the HNBR/(p)CBT hybrid during heating and cooling

results claiming that $\mathrm{pCBT}$ crystallization is of stochastic nature [6]. In the subsequent temperature range two melting peaks can be found: at $T \approx$ $130^{\circ} \mathrm{C}$ and $T \approx 220^{\circ} \mathrm{C}$. The first one should be assigned to the melting of the unpolymerized CBT, whereas the second one to the melting of the pCBT formed. The small exotherm at $T \approx 105^{\circ} \mathrm{C}$ may be linked with the cold crystallization of (p)CBT. During subsequent cooling the $\mathrm{pCBT}$ crystallizes at $T \approx 165^{\circ} \mathrm{C}$. As the related enthalpy value is markedly higher $(13.6 \mathrm{~J} / \mathrm{g})$ than that of the melting from the $1^{\text {st }}$ heating $(<1 \mathrm{~J} / \mathrm{g})$, one should presume that $\mathrm{pCBT}$ has been formed during the $1^{\text {st }}$ heating instead of the HNBR curing process. Note that such peculiar thermal behaviour was already reported for the in-situ bulk polymerization of CBT $[10,11]$. The $2^{\text {nd }}$ heating curve displays again the $T_{g}$ of HNBR. On the other hand, the $T_{g}$ step of the pCBT can hardly be resolved. This is due to the high crystallinity of the pCBT present. The melting peak of pCBT can be found at $T \approx 215^{\circ} \mathrm{C}$ in accord with the expectation. The crystallization (cooling) and melting enthalpies $\left(13.8 \mathrm{~J} / \mathrm{g}\right.$ in the $2^{\text {nd }}$ heating) are closely matched.

The DMTA curves in Figure 3 give further insight in the phase structure. The fact that the storage modulus $\left(E^{\prime}\right)$ vs. temperature shows only one drop, viz. at the $T_{g}$ of HNBR, substantiates that HNBR forms the continuous whereas (p)CBT the disperse phase. The designation (p)CBT considers that likely a small portion of CBT polymerized and its major fraction remained unpolymerized under the HNBR curing cycle. This, suggested by the DSC tests, will be corroborated by further results later. Nonetheless, (p)CBT works as an active filler of 

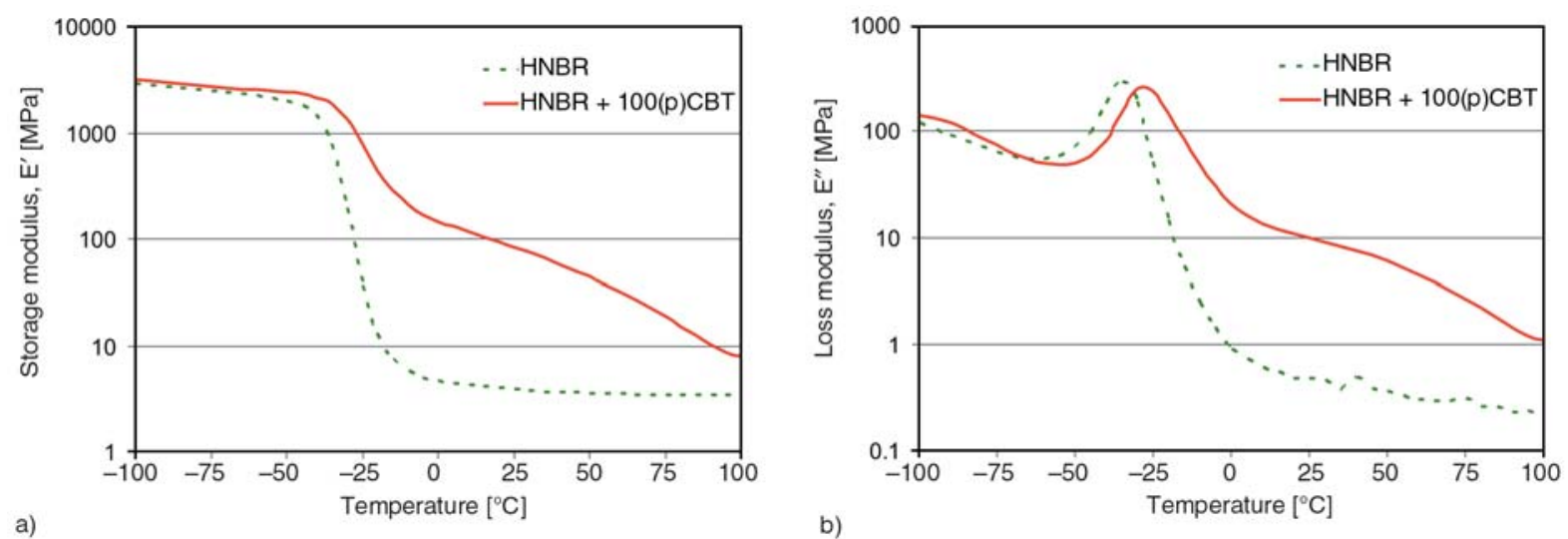

Figure 3. $E^{\prime}$ vs. $T$ (a) and $E^{\prime \prime}$ vs. $T$ (b) traces for the HNBR and HNBR/(p)CBT hybrid

Table 1. Comparison of the properties of HNBR and HNBR/(p)CBT

\begin{tabular}{|c|c|c|}
\hline & HNBR & HNBR + 100(p)CBT \\
\hline $\tan \delta$ at the actual $T_{g}$ of HNBR [1]* & 1.360 & 0.337 \\
\hline Density $\left[\mathrm{g} / \mathrm{cm}^{3}\right]$ & 1.057 & 1.137 \\
\hline Shore A hardness & 42 & 82 \\
\hline Martens hardness, HM [MPa] & 1.45 & 18.1 \\
\hline M-100 [MPa] & 1.3 & 3.4 \\
\hline M-200 [MPa] & 2.7 & 4.4 \\
\hline Tensile strength [MPa] & 4.4 & 9.6 \\
\hline Strain at break [\%] & 280 & 467 \\
\hline Tear strength $[\mathrm{kN} / \mathrm{m}]$ & 4.2 & 33.6 \\
\hline E-modulus at $0.01 \%$ strain from DMTA at $T=25^{\circ} \mathrm{C}[\mathrm{MPa}]$ & 4 & 84 \\
\hline
\end{tabular}

*Note: the $T_{g}$ of the $\operatorname{HNBR}\left(-25^{\circ} \mathrm{C}\right)$ increased in presence of (p)CBT $\left(-19^{\circ} \mathrm{C}\right)$

thermoplastic nature. The latter is reflected by the steady decrease of $E^{\prime}$ with increasing temperature. That is the reason why no plateau modulus appears. The 'active' filler character of (p)CBT is well reflected by the enhanced $E^{\prime}$ compared to that of the plain HNBR (of Figure 3a). Note that the $T_{g}$ peak of the HNBR, when read at the peak position of the $E^{\prime \prime}$ vs. $T$ trace, shifted toward higher temperatures in presence of (p)CBT (cf. Figure $3 b$ and Table 1). This means that the segmental motion of HNBR has been hampered by the (p)CBT present. Considering the fact that this experimental HNBR contains some acrylate moieties, grafting between HNBR and (p)CBT is most likely to occur, namely via transreactions. This would explain the observed shift in the $T_{g}$. The less developed shoulder at $T \approx 50^{\circ} \mathrm{C}$ in the $E^{\prime \prime}$ vs. $T$ trace of the hybrid may be a further hint for this kind of grafting which affects the chain mobility. Note that the $T_{g}$ relaxation of the amorphous pCBT should appear in this range, too.

\subsection{Hardness and mechanical properties}

Figure 4 shows the load vs. penetration depth curves of the microhardness measurement for three consecutive loadings. In contrast to HNBR, the relative residual deformation is higher for the hybrid after this test series. This is due to the plastic deformability of the amorphous pCBT and due to the break-up crystal clusters of recrystallized CBT

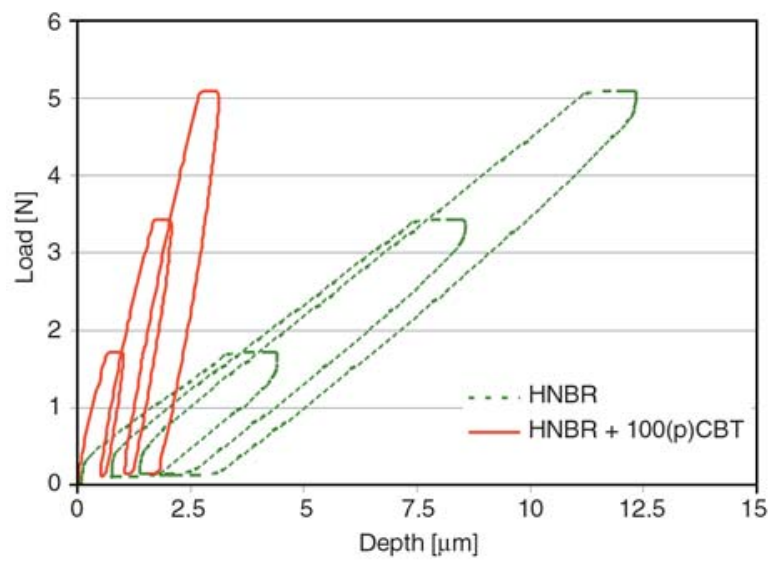

Figure 4. Load vs. penetration depth curves for three consecutive loading/deloading cycles during microhardness measurements on the systems studied 
(the latter will be explained later). Note that this behaviour may strongly influence the sliding wear under POP conditions, where recovery effects are of great importance.

The hybridization was associated with considerable increase in both Martens and Shore A hardness values (cf. Table 1). Characteristic stress-strain curves

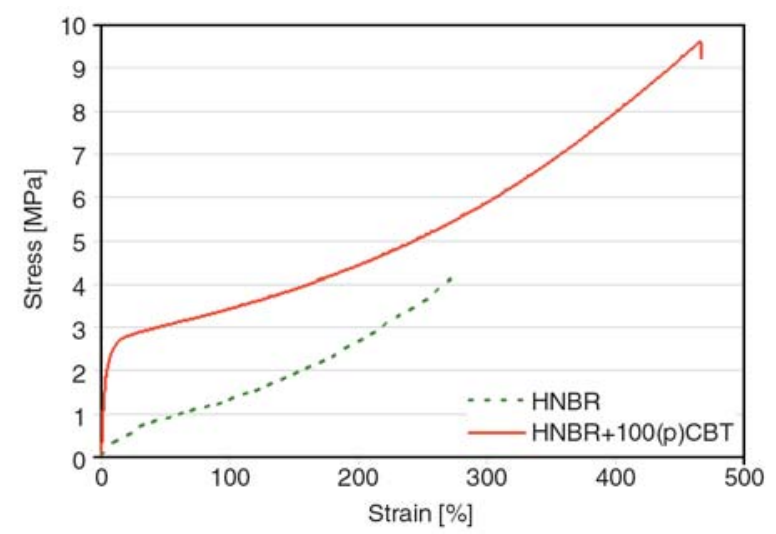

Figure 5. Comparison of the stress vs. strain behavior of HNBR and HNBR/(p)CBT hybrid

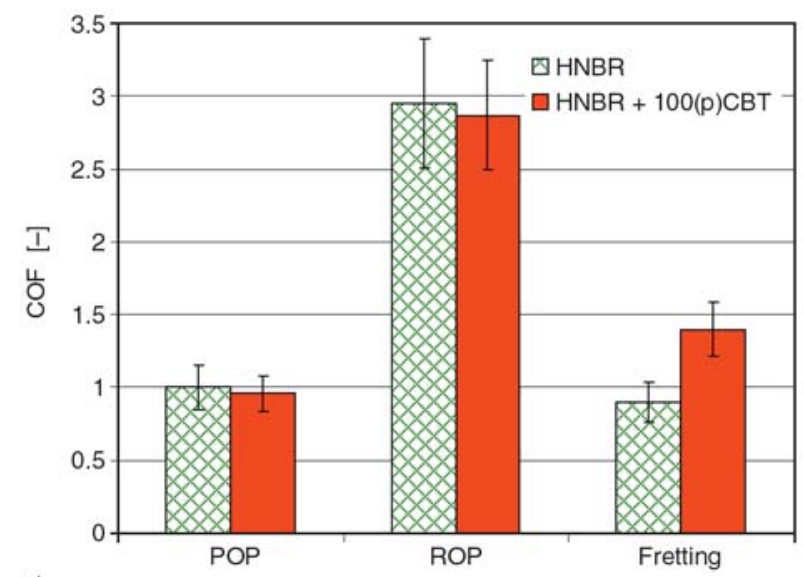

a)

Figure 6. Measured steady-state coefficient of friction (COF) values (a) and specific wear rate data (b) in the POP, ROP and fretting tests

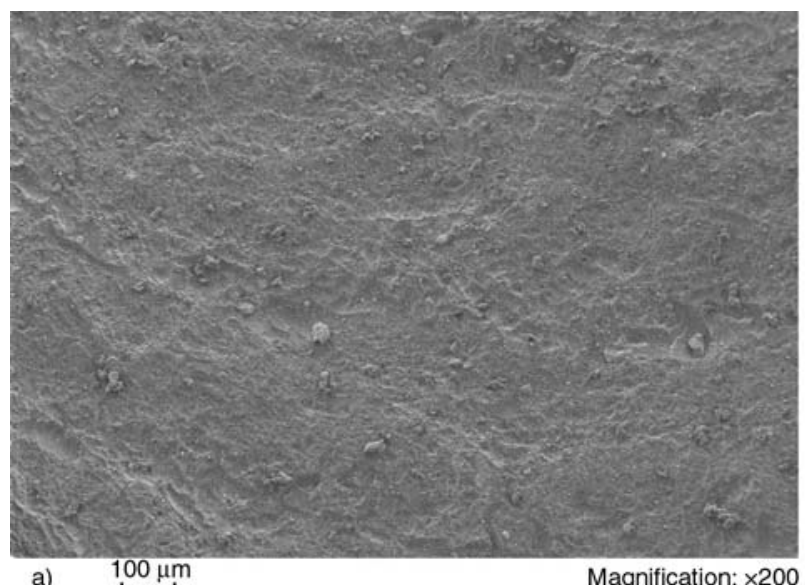

for HNBR and HNBR/(p)CBT are shown in Figure 5. Interestingly, incorporation of CBT increased both ultimate stress and strain simultaneously, i.e. this material worked as an active filler.

HNBR/(p)CBT hybrid outperformed HNBR in respect to the tear strength, as well. Results of the hardness and mechanical tests are summarized in Table 1.

\subsection{Friction and wear}

Figure 6a shows the steady-state COF of the HNBR and $\mathrm{HNBR} /(\mathrm{p}) \mathrm{CBT}$ hybrid as a function of the tribotests. One can notice a marginal decrease in the COF due to CBT modification for both POP and ROP, while the opposite trend appears for fretting. The specific wear rate of HNBR was reduced by CBT hybridization under both POP and ROP conditions (in the latter case more prominently). On the other hand, an adverse tendency was observed for fretting.

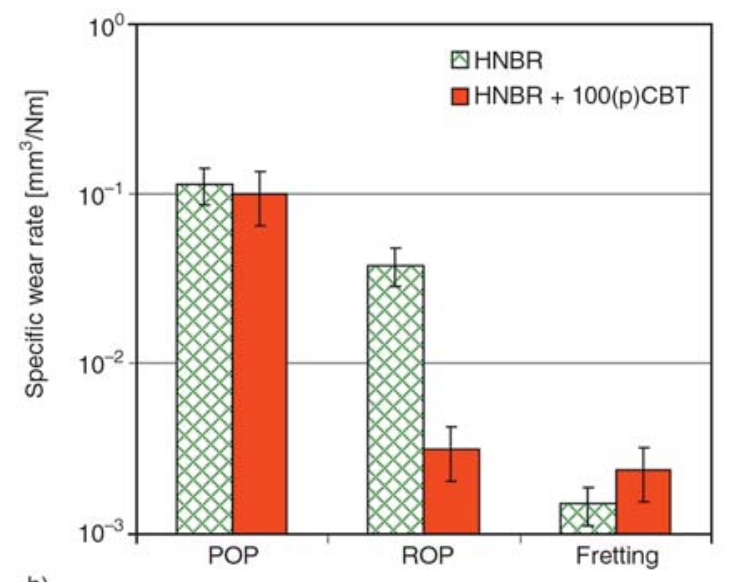

b)

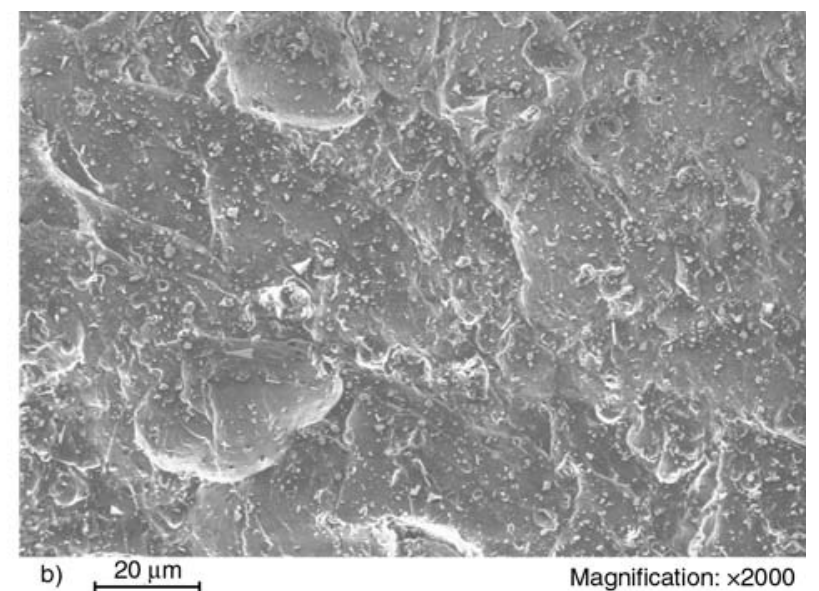

b) $20 \mu \mathrm{m}$

Figure 7. SEM pictures taken from the wear track of plain HNBR after POP test. Note: sliding direction is downwards. (Magnification: $\mathrm{a}-\times 200, \mathrm{~b}-\times 2000$ ) 

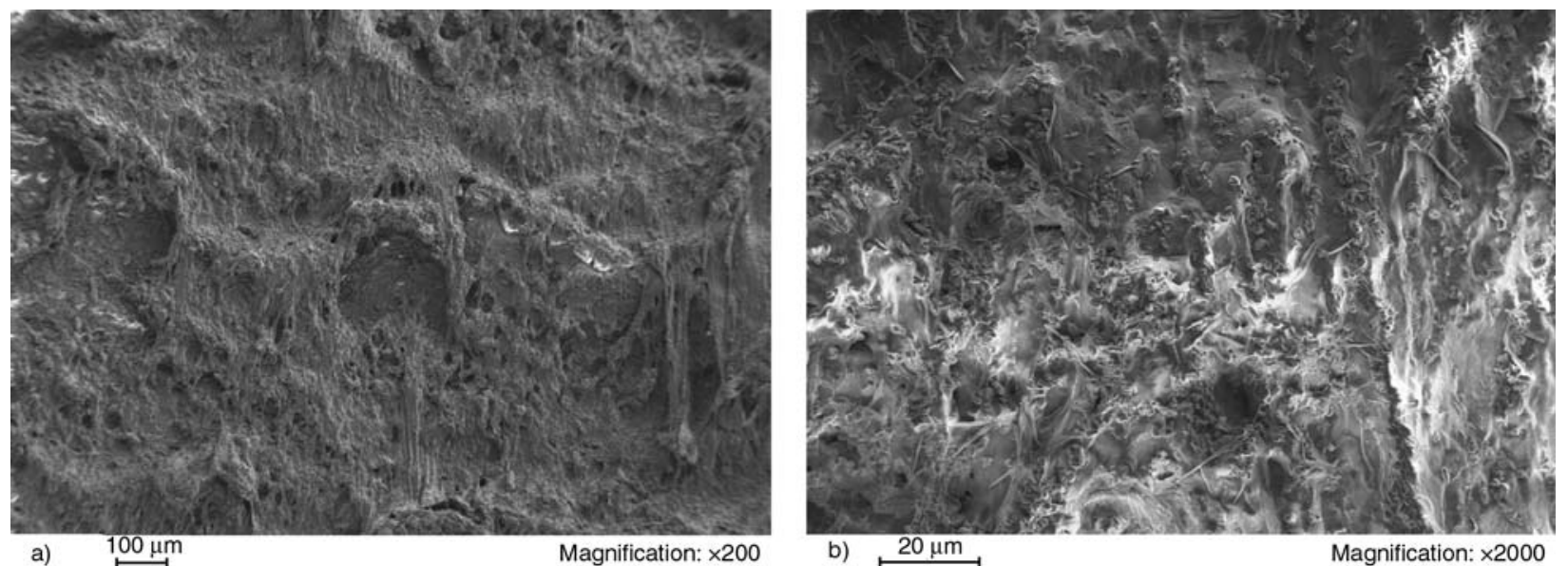

Figure 8. SEM pictures taken from the wear track of HNBR/(p)CBT after ROP test. Note: sliding direction is downwards. (Magnification: $\mathrm{a}-\times 200, \mathrm{~b}-\times 2000$ )

The wear mechanisms were elucidated for the systems after POP tests. The wear track of the plain HNBR showed that debris were chipped off, generating some craterlike structure - cf. Figure 7 . Note that this is the usual failure mode under sliding wear for unfilled rubbers ([12] and references therein). The worn surface after POP became more rough in presence of (p)CBT (cf. Figure 8). This is in line with the change observed for the COF data. On the other hand, the worn surface of the HNBR/ (p)CBT reveals that prominent 'plastic type' deformation occurred. Fibrils, remnants of a disrupted fibrillar structure, being elongated to the sliding direction, are indicators of this plastic deformation. Recall, that this is supported by the formation of amorphous $\mathrm{pCBT}$ and also in accord with the break-up of CBT crystal clusters, the existence of which will shown later. Moreover this failure mode could be predicted based on results of the cyclic microhardness tests. Nevertheless, chipping phenomena are still discernible on the worn surface (cf. Figure 8a). High magnification SEM picture (cf. Figure $8 \mathrm{~b}$ ) may hint for effects of locally emerging high flash temperatures. This may cause the polymerization and crystallization of CBT and pCBT, respectively, in analogy with the DSC results (cf. Figure 2). The high magnification SEM picture in Figure 9 delivers the strongest argument for the fact that CBT practically did not polymerize under the curing schedule of HNBR. In the worn surface well developed, micron-scale crystals of plate and prism shapes are well resolved. They should have been formed via recrystallization from the CBT melt. Recall that the CBT melting range is between

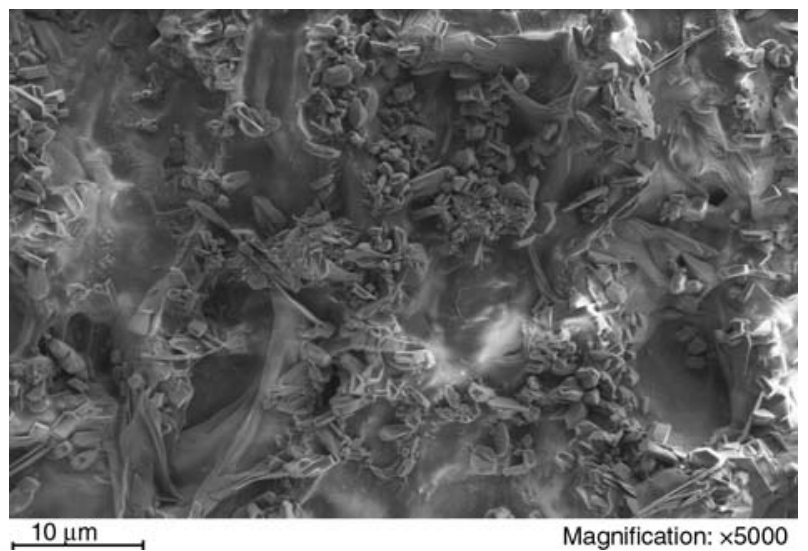

Figure 9. SEM picture taken from the worn surface of HNBR/(p)CBT after POP test (Magnification: $\times 5000)$

$T=140-150^{\circ} \mathrm{C}$, whereas that of the HNBR curing was $T=190^{\circ} \mathrm{C}$ in this case. So, if CBT did not polymerize, then it had to recrystallize from the melt during the cooling period after curing. The related large crystals of high aspect ratio worked as reinforcing filler in the HNBR. We have further proofs for the above scenario. Preliminary results from extraction (using chloroform, which already at ambient temperature completely dissolves CBT unlike pCBT) and wide-angle X-ray scattering (WAXS) experiments support that only a very small portion of CBT has been polymerized under the cure conditions set.

This observation is of great practical relevance due to the following aspects. First, incorporation of CBT, even if it does not polymerize under the curing conditions of rubber, may strongly improve the flow behaviour of the related rubber. Recall that the melting temperature of CBT is lower than the usual 
cure temperature of rubbers and its melt viscosity is very low [9]. Second, the subsequent recrystallization of CBT - during cooling of the cured rubber results in the formation of microscopic crystals and crystal agglomerates which have high aspect ratio, and thus may work as efficient reinforcements in rubbers. The prerequisite of the latter is a good interfacial bonding between the rubber and (p)CBT. It has to be clarified next how the necessary interfacial bonding between (p)CBT and other rubbers can be achieved.

\section{Conclusions}

In this work HNBR/CBT hybrids were produced by incorporating cyclic butylene terephthalate oligomers (CBT) in a peroxide-curable HNBR. The CBT, added in 100 parts per hundred parts rubber (phr) amount, was dispersed in the HNBR matrix. According to DSC results the majority of the CBT did not polymerize under the curing of the HNBR rubber. On the other hand, CBT is still able to undergo polymerization/crystallization when the HNBR/CBT hybrid is heated and/or hold above the melting temperature of polybutylene terephthalate. Instead of polymerization, the CBT was molten during the HNBR curing. In the follow-up cooling of HNBR the CBT recrystallized into micronscaled crystals of high aspect ratio. This was the major reason for the improvements in both mechanical properties and resistance to dry sliding. So, the CBT crystals worked as active filler particles of thermoplastic nature and improved the mechanical and tribological performance of the HNBR prominently. Incorporation of CBT affected the coefficient of friction (COF) only slightly (being dispersed in the HNBR matrix) by contrast to the specific wear rate. The specific wear rate was markedly reduced under POP and ROP testing, whereas it increased in fretting test for the hybrid compared to the plain HNBR.

\section{Acknowledgements}

This work was performed in the framework of a bilateral cooperation between Hungary and Germany (MöB and DAAD) and an integrated project of the EU (KRISTAL; Contract Nr.: NMP3-CT-2005-515837; www.kristal-project.org). The authors are thankful to Dr. M. Mezger (Lanxess) for providing the HNBR along with additional remarks to this topic.

\section{References}

[1] Legge N. R., Holden G., Schroeder H. E.: Thermoplastic elastomers. Hanser, München (1987).

[2] Coran A. Y., Patel R. P.: Thermoplastic elastomers by blending and dynamic vulcanization. in 'Polypropylene: Structure, Blends and Composites' (ed.: KargerKocsis J.) Chapman and Hall, London, Vol 2, 162-201 (1995).

[3] Karger-Kocsis J.: Thermoplastic rubbers via dynamic vulcanization. in 'Polymer Blends and Alloys' (eds.: Shonaike G. O., Simon G. P.) Marcel Dekker, New York, 125-153 (1999).

[4] Brunelle D. J.: Synthesis and polymerization of cyclic polyester oligomers. in 'Modern Polyesters' (eds.: Scheirs J., Long T. E.) Wiley, Chichester, 117-142 (2003).

[5] Parton H., Baets J., Lipnik P., Goderis B., Devaux J., Verpoest I.: Properties of poly(butylene terephthalate) polymerized from cyclic oligomers and its composites. Polymer, 46, 9871-9880 (2005).

[6] Harsch M., Karger-Kocsis J., Apostolov A. A.: Crystallization-induced shrinkage, crystalline, and thermomechanical properties of in situ polymerized cyclic butylene terephthalate. Journal of Applied Polymer Science, 108, 1455-1461 (2008).

[7] Park E. H.: Dynamic vulcanization of elastomers with in-situ polymerization. US Patent 7351769 , USA (2008).

[8] Papke N., Karger-Kocsis J.: Thermoplastic elastomers based on compatibilized poly(ethylene terephthalate) blends: Effect of rubber type and dynamic curing. Polymer, 42, 1109-1120 (2001).

[9] Mohd Ishak Z. A., Gatos K. G., Karger-Kocsis J.: On the in-situ polymerization of cyclic butylene terephthalate oligomers: DSC and rheological studies. Polymer Engineering and Science, 46, 743-750 (2006).

[10] Karger-Kocsis J., Shang P. P., Mohd Ishak Z. A., Rösch M.: Melting and crystallization of in-situ polymerized cyclic butylene terephthalates with and without organoclay: A modulated DSC study. Express Polymer Letters, 1, 60-68 (2007).

[11] Mohd Ishak Z. A., Shang P. P., Karger-Kocsis J.: A modulated DSC study on the in situ polymerization of cyclic butylene terephthalate oligomers. Journal of Thermal Analysis and Calorimetry, 84, 637-641 (2006).

[12] Karger-Kocsis J., Felhős D.: Friction and sliding wear of 'nanomodified' rubbers and their coatings: Some new developments. in 'Tribology of Polymeric Nanocomposites' (eds.: Friedrich K., Schlarb A. K.) Elsevier, Amsterdam, 304-324 (2008). 